\title{
Factors involved in breast cancer treatment choice and their impact on patients' resilience
}

\author{
Irina Crumpei* \\ Post-PhD Fellow, SOP HRD/159/1.5/S/133675 Project, Romanian Academy lasi Branch
}

\begin{abstract}
Treatment choice in oncology is a difficult, complex process. The cancer diagnosis meets the criteria for a traumatic event and patients are overwhelmed with negative emotions. In this vulnerable moment, women with early breast cancer have to decide between mastectomy and breast conserving surgery, adjuvant therapies and breast reconstruction. Quality decision making and optimal communication with their doctors are strongly associated to resiliency in post-treatment phase. We examined patients' knowledge of their treatment options, their involvement in the decision making process and the relationship to quality of life. 154 early-stage breast cancer patients took part in the study. Our results highlight important deficiencies in patients' knowledge about breast cancer treatment, their communication with the medical team and their implication in the decision making process. Even years after completing the treatment, poor information and communication is associated with ambivalence and low quality of life.
\end{abstract}

Keywords: breast cancer, decision quality, quality of life, resilience

\section{Introduction}

Breast cancer is the most common malignancy in women [1]. This is also true in Romania, where the Ministry of Health reported an increase of over $15 \%$ in breast cancer incidence in the past decades. In 2006 it reached a rate of 50.56 per thousand women [2]. Moreover, Romania presents a worrisome increase in breast cancer mortality of $17 \%$ while in Western Europe mortality decreased with varying rates of up to $45 \%$ [3]. One reason for the reversed Romanian trend might be delayed diagnosis which is associated with a poorer prognostic. In this context, resiliency in breast cancer patients could be operationalised as prompt seeking of medical advice.

Received: May 2015; Accepted after review: June 2015; Published: June 2015.

${ }^{*}$ Corresponding author: Irina Crumpei, Post-PhD Fellow, Romanian Academy lasi Branch, 2 T. Codrescu str. lasi, 700481, Romania.

Email: irina crumpei14@yahoo.com
On the other hand, resiliency remains a processual ability to positively adjust to cancer's challenges along the treatment and post-treatment continuum [4]. Progress in oncology research improved survivorship in all cancer patients changing the focus from simply surviving to quality living after cancer. Resiliency became a central concept in cancer research as quality of life and distress became the sixth vital sign along with temperature, respiration, heart rate, blood pressure and pain [5-7]. Quality of life is challenged as soon as the first symptoms appear. Around one third of women postpone seeking medical advice for more than three months [8]. In Romania avoidance might be even higher as most women are diagnosed in advanced stages of the disease [9, 10]. Breast cancer patients' fear, hopelessness and guilt are factors associated to the delayed diagnosis $[11,12]$. They open a vicious circle with strong negative conseuqences on survival and quality of life. 
Waiting for the biopsy results and diagnosis are very emotional moments when despair, fear of death, loss of control and hopelessness are often reported [13]. Furthermore, receiving a breast cancer diagnosis meets the criteria of a full traumatic event [14]. Distress and perceived threat are stronger imediately after diagnosis than after surgery [15]. Even if most patients don't report clinical levels of distress showing resilience [16], an important percent of them will develop depression, suiccidal ideation or generalised anxiety following the diagnosis [17]. Quality of emotional adjustment and coping strategies used in diagnosis and treatment phase are important predictors of quality of life and well being in post-treatment phase [13, 18]. There are individual characterstics associated to an optimal adjustment. Internal locus of control, positive coping, optimism, openness, active acceptance of the diagnosis $[18,19]$.

Decision quality and perceived involvment in treatment choice are also important predictors of post-treatment adjustment [20, 21]. Women with breast cancer have to make several essential choices: what represents a suspicious symptom, how long to postpone seeking medical advice, which is the best surgery option, what adjuvant treatment to choose, opting for breast reconstruction, frequency of post-treatment screening, etc. Most decisions are needed at a time when these patients are highly vulnerable and emotional.

Decision quality is an evolving concept. Traditionally, informed consent requires autonomous authorisation of the medical procedure along with the principle of non control [22]. Patients should be well informed and allowed to decide about the treatment they prefered. However noncontrol is difficult to accomplish especially when research shows that most patients prefer to share responsability of decision making [21, 23, 24]. Patients' ideal level of participation in decision making varies greatly.

A study on 368 breast cancer patients shows that while $72 \%$ of them report being happy with their involvement, $21 \%$ thought they had too much responsibility and $7 \%$ wished to be more involved [25]. Nattinger et al (1992) observed that decision about breast cancer treatment depended more on patients' geographical location and their doctor than on their preferred treatment option [26]. Therefore, decision quality becomes a complex process where patients' need for information, advice and shared responsibility should be met in a personalized manner. Younger patients opt for more involvement, while older women are more willing to delegate responsibility [27].

The initial phase of confusion and denial renders treatment choice difficult and patients avoid making decisions. Their willingness to participate changed as they accept their illness and start to adjust [28]. Even when they don't want to assume responsibility of decision making, patients still ask to be well informed [23, 29]. Thorough information and communication with medical staff satisfies their need for autonomy and is associated to post-treatment well-being [29]. On the other hand, doctors tend to overestimate patients' wish to take part in decision making and to underestimate their need for information [30]. As a consequence, a quarter of the women feel overwhelmed by the responsibility of decision making [25]. Often they don't fully understand the consequences of their decision and end up feeling regret and guilt [31]. However, studies on decision regret show that women most often regret inactions than actions and insufficient participation in decision making is one of their complaints [32].

Literature on decision quality and its impact on resilience and quality of life are still controversial.

Romania presents a higher risk of compromising the decision making process. Firstly, it lacks a national psychosocial program for cancer patients. The focus in cancer care is still highly cure oriented. Secondly, both the patients and the medical staff show a higher acceptance of the paternalistic model in decision making. Finally, there is a shortage of medical staff which renders thorough communication with the patients very difficult.

The goal of our study was to assess patients' knowledge of their treatment options, quality of communication with the medical staff, shared decision making and the relationship to quality of life. 


\section{Material and Method}

One hundred and fifty-four early-stage breast cancer patients took part in the study. They were recruited in 3 medical establishments in lași where they came for the periodic medical examination. Their average age was 55 year-old $(S D=10) .60 \%$ underwent mastectomies and $40 \%$ had breast conserving surgeries (lumpectomies). In average patients were assessed 5 years after diagnosis. Patients with bilateral mastectomies, breast reconstructions or with recurrences were not included. Women were told about the study and asked to answer a set of questionnaires. Written informed consent was obtained from the patients for publication of the study results.

Decision Quality Instrument [33] was used to assess decision quality. The scale has three different factors: knowledge of facts about breast cancer ( $\alpha=0.60)$, a concordance score and a decision process score $(\alpha=0.77)$. The first factor assesses women's knowledge of some essential facts about breast cancer and its treatment. Items offer multiple choices with only one correct answer. Patients are asked about survival rates, surgery side effects and differences between lumpectomy and mastectomy. A higher score means better knowledge about breast cancer and treatment options.

The concordance factor assesses the concordance between patients' preferred treatment, their goals and concerns and the received treatment. Women have to rate on an
11 point scale how important was to them to keep their breast or to avoid having radiation. The third section assesses if patients were offered a choice, how much the advantages and disadvantages of each intervention were discussed and whether their preference mattered in the decision process.

The Quality of Life Index (QLI) - Cancer III Version [34] was used to measure quality of life in terms of satisfaction with life. The index measures both satisfaction and importance regarding different aspects of life. Final scores report satisfaction with the aspects of life valued by the person. It contains 4 sub-scales which offer independent scores measuring satisfaction on different domains: health and functioning ( $\alpha=0.80)$, psychological/spiritual $(\alpha=0.84)$, social and economic $(\alpha=0.73)$ and family ( $\alpha=0.75$ ). The items can be added to generate a total quality of life score $(\alpha=0.90)$.

\section{Results}

Firstly we undertook a descriptive analysis to better understand patients' options and knowledge about their illness at the time of treatment choice. Whatever their surgical intervention, more than half of patients answered it was important for them to keep their breast. However, $83 \%$ of patients with mastectomy answered they preferred to have their breast removed for peace of mind. 50\% of patients with conservative surgery gave the same answer (Figure 1).

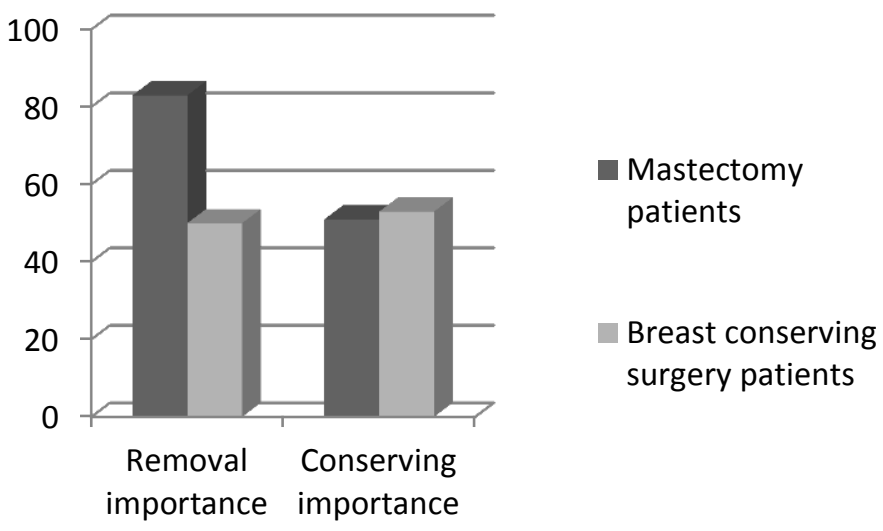

Fig.1. Patients perceived importance after removing/keeping their breast 
Ninety-three\% of women believe that postponing the operation for some time has an important impact on their chances of survival. $30 \%$ of women believe that most of breast cancer patients finally die of cancer in spite the early diagnosis and the right treatment.

Only $46 \%$ of women with lumpectomy know that this type of intervention has a slightly higher risk of recurrence and $28 \%$ know they have a higher chance of needing additional surgeries. Only $28 \%$ of all patients know that both types of surgical interventions have similar survival rates for early diagnosed breast cancer (Figure 2).

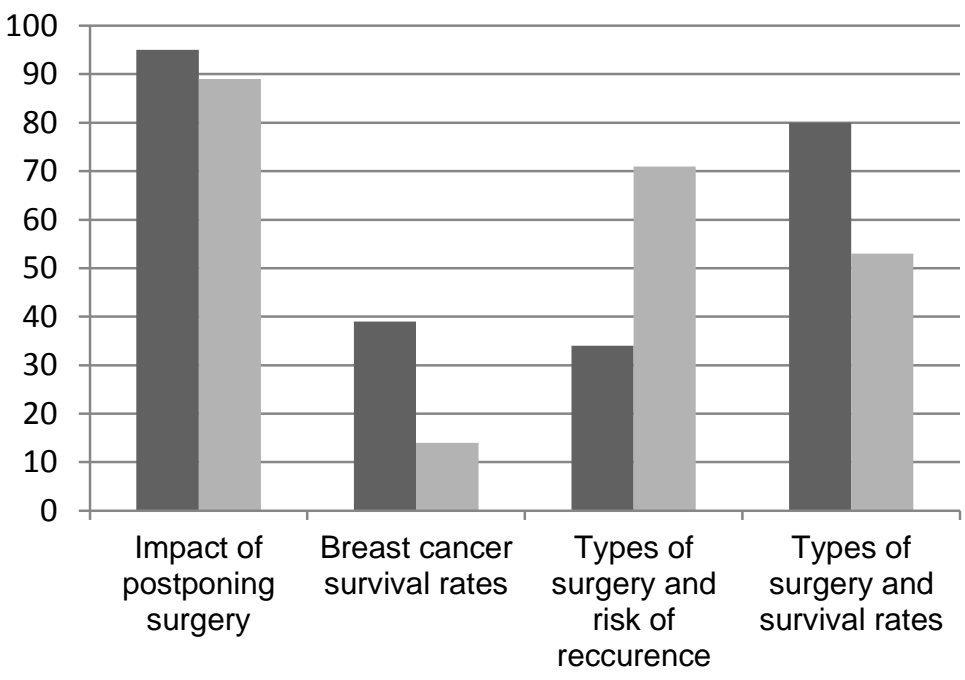

- Mastectomy patients

Breast conserving patients

Fig. 2. Patients who have misconception about aspects of treatment

When asked about their communication with the medical staff $14 \%$ of patients with mastectomy and $43 \%$ of patients with lumpectomy, answer they were never told about the mastectomy option. Forty-six per cent of patients with mastectomy say they didn't discuss at all with their doctor about the disadvantages of mastectomy. Sixty-three per cent of patients with mastectomy and $28 \%$ of patients with lumpectomy never discussed with the medical team about the breast conserving surgery. Forty-six per cent of patients with lumpectomy weren't told about the disadvantage associated with their treatment choice. Thirty-nine per cent of all patients say they were never asked about the surgery option they preferred (Figure 3).

Patients were asked two questions about how important it was to them to either keep their breast or to entirely remove it to gain peace of mind. We reversed the second item and calculated a total score showing the importance of keeping the breast. Independent Samples T Tests were conducted to assess the difference between women with mastectomy and those with conservative surgery. Results show as expected, that women with conservative surgery, reported higher scores for the importance of conserving the breast $(M=10.45, S D=4.74)$ compared to patients with mastectomy $(\mathrm{M}=6.95, \mathrm{SD}=$ 4.66; $\mathrm{t}(130)=-4.12, \mathrm{p}<0.001)$. However there are patients who wished to keep their breast and underwent mastectomy despite their early stage. More than $30 \%$ of patients with mastectomy chose scores over the average to show the importance of conserving their breast.. 


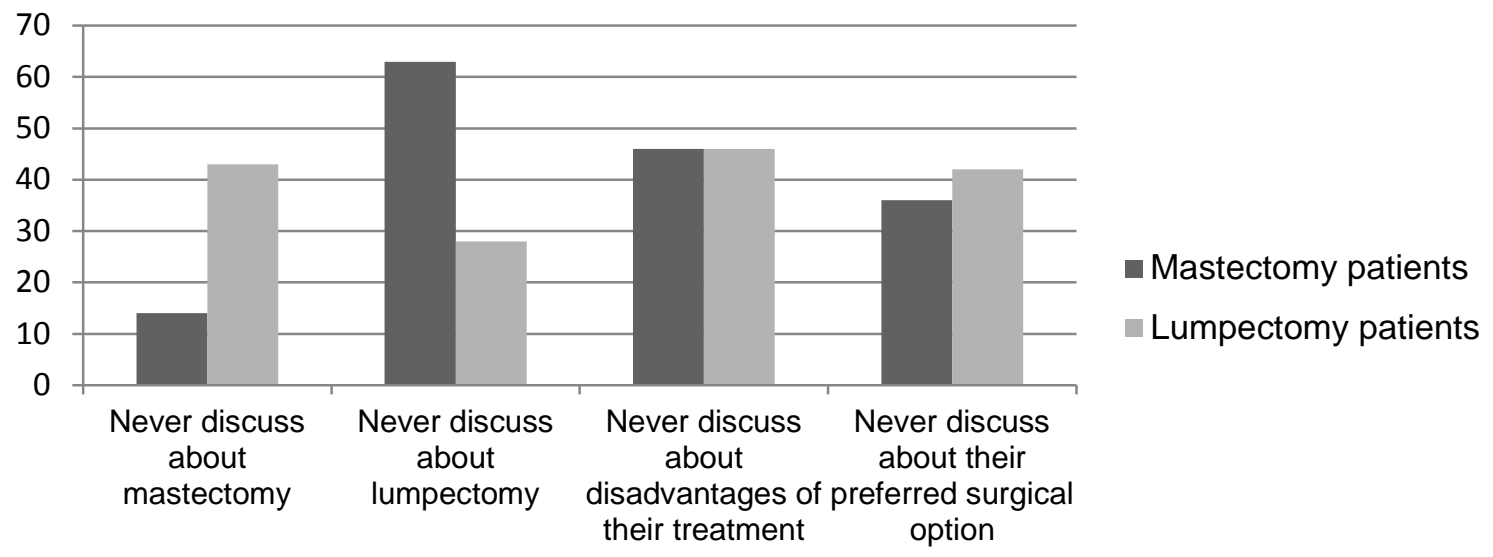

Fig. 3. Deficiencies in the communication with the medical staff

We conducted correlations to evaluate the relationship between the perceived importance of conserving the breast and the quality of life for patients with mastectomy and conserving surgery separately. We only found significant correlations for patients with mastectomy. Results show negative average correlations for all four domains of quality of life suggesting that patients who wished to keep their breast and lost it have poorer physical, psychological, social and family quality of life.There is no association between quality of life domains and perceived importance of keeping the breast in women with conservative surgery (Table 1).

Table 1. Pearson correlation: quality of life and perceived importance of breast conservation

\begin{tabular}{lccccc}
\hline & Total QLI & Health & Social & Psychological & Family \\
\hline Mastectomy & $-.46^{\star *}$ & $-.39^{* \star}$ & $-.46^{* *}$ & $-.50^{* *}$ & $-.39^{\star *}$ \\
\hline Lumpectomy & .11 & .16 & .04 & .01 & .22 \\
\hline
\end{tabular}

Note: ${ }^{*}=\mathrm{p}<.05,{ }^{* *}=\mathrm{p}<.01 . \mathrm{N}=84$ for mastectomy patients, $\mathrm{N}=48$ for lumpectomy patients

Independent $\mathrm{T}$ Tests were conducted to compare the perceived length of discussion with the medical staff about each intervention between the two groups of patients. There are no significant differences in the quantity of information received about mastectomy ( $t$ $(140)=-0.74, p=0.45)$. Women with mastectomy $(\mathrm{M}=6.57, \mathrm{SD}=1.73)$ and lumpectomy $(\mathrm{M}=6.82, \mathrm{SD}=2.18)$ discussed an equal amount of time about mastectomy with the medical staff. On the other hand, there are significant differences in the time spent to discuss about lumpectomy $(\mathrm{t}(140)=$ $3.88, p<.001)$. This option was examined a lot less with the mastectomy patients. Overall, paired samples $T$ Test results show that medical staff discuss significantly more with their patients about mastectomy than about lumpectomy $(\mathrm{t}(151)=-4.29, \mathrm{p}<0.001)$.

Independent Samples $T$ Test also show better quality of life in patients who were asked what their treatment option was $(M=22.09$, $\mathrm{SD}=4.58$ ) compared with those who weren't asked their opinion $(M=20.35, S D=5.70 ; t$ $(148)=1.96, p=0.041)$. In general, patients who report communicating more with the medical staff about treatment options show significantly higher quality of life on all factors and on the total score $(M=22.15, S D=4.08$, $\mathrm{M}=20,13, \mathrm{SD}=6.17, \mathrm{t}(150)=2.25, \mathrm{p}=$ 0.026 ). 
Thirty per cent of women believe they have high chances of dying of cancer despite the early diagnosis and the right treatment. Those who have these believes show significantly lower quality of life $(M=19.72$, SD $=4.20$ ) compared to women who know that with the right treatment they may have a normal life expectancy $(M=21.94, S D=5.32$, $\mathrm{t}(152)=2.51, \mathrm{p}=.013)$.

\section{Discussions}

Results show high ambivalence among breast cancer patients' in post-treatment phase. Half of the patients with mastectomy feel it was important for them to keep their breast and half of the patients with breast conserving surgery rate high the importance of having their breast removed for peace of mind. Current research reflects this ambivalence. On one hand, women mostly feel regret for inactions, things they didn't do. Not choosing the mastectomy option is one such regret [32]. On the other hand, around half of patients never discussed the other type of surgery and $39 \%$ say they were never asked what they preferred. Ambivalence could be generated by their lack of involvement in the decision making process. Patients who had mastectomies, but wished they have kept their breasts have lower quality of life. These results highlight the importance of quality decision making and contradict results about inactions causing more decision regret [32]. Patients with breast conserving surgery show ambivalence but there is no relationship with quality of life in their case. It might be that the irreversible, invasive nature of mastectomies and the low rate of breast reconstructions in Romania cause the higher impact on quality of life. Ambivalent lumpectomy patients always have the option of entirely removing their breast. Knowing this might make their ambivalence less distressing.

Only half of the patients discussed with the medical staff about the disadvantages of the intervention they have finally chosen. The other half had to learn about the consequences as they happened. Obviously these patients didn't benefit of an optimal informed consent. Answers at the knowledge scale reflect their limited understanding of breast cancer and the treatment they "chose". More than half of patients with breast conserving surgery don't know that they stand a slightly higher risk of recurrence than women who underwent mastectomies. Another result with similar consequences is that seventy percent of all women didn't know that the two surgical interventions had comparable survival rates. These results are consistent with previous research showing how relative informed consent really is [35]. In other studies patients report that survival and recurrence are among the most important factors they considered in treatment decision making [35]. It is obvious how better communication with the patients could have changed the treatment choices they made.

Almost one third of women believe that most breast cancer patients finally die of cancer in spite of the early diagnosis and the right treatment, when in fact, most of them will have normal life expectancies. These women have significantly lower quality of life. Fear of recurrence and fear of death are probably among the factors explaining this relationship. Accurate information could help resolving these worrisome results.

Ambivalence and decision regret could benefit greatly from better judgements during the treatment choice process. More time to think, to gather information and weigh the options is an affordable commodity for early diagnosed patients [28]. They can take up to a couple of weeks before deciding for the treatment they want. More than ninety percent of women who took part in our study answered that any delay in surgery would decrease the survival rates. Having such convictions it is no wonder that they felt pressured and delegated responsibility for treatment decisions.

Results show that the medical staffs discusses more about mastectomy than about breast conserving surgery. This might mean that patients with mastectomy are less often informed about the breast conserving option.

Only one third of the patients in our sample reported that they had been asked what their surgery preference was. Patients who were asked what they preferred and who report communicating more with the medical staff show higher quality of life. This is 
consistent with previous research about the importance of optimal communication with the medical team in patients' post-treatment quality of life [28, 29]. Doctors tend to underestimate patients' need for information while patients repeatedly report the need to be better informed in medical settings [36].

\section{Conclusions}

Treatment choice in oncology is a difficult, complex process. Patients are vulnerable, in a highly emotional state and they have to decide about life changing procedures and adjuvant treatments with strong side effects. Many times patients will need their doctor's help to choose but their need for participation in the decision making process varies greatly from one person to another. The need for complete information and communication with the medical staff is much more universal. Current research shows medical professionals tend to overestimate patients' need for involvement in decision making and underestimate their need for information. The Romanian medical system still struggles with a prolonged economical transition. There is insufficient medical staff for the high number of patients. Low salaries often force them to work longer hours. In this context, medical professionals have less time and disponibility to efficiently communicate with patients. Moreover, there is no psychosocial focus in Romanian oncological care. Medical professionals have no training on psychosocial interventions or efficient communication with patients. Treatment is targeted to cure the physical symptoms. Consequently, our results highlight important deficiencies in patients' knowledge about breast cancer treatment, their communication with the medical team and their implication in the decision making process. Even years after completing the treatment, poor information and communication is associated with ambivalence, low quality of life and reduced resilience. As quality of life became the sixth vital sign, oncological care should make it one of the priorities. Improving the quality of the decision making process and the general communication with the patients, might be a good place to start.

\section{Acknowledgement}

This paper is supported by the Sectoral Operational Programme Human Resources Development (SOP HRD), financed from the European Social Fund and by the Romanian Government under the contract number POSDRU/159/1.5/S/133675.

\section{References}

1. World Health Organisation. "Breast cancer: prevention and control" [http://www.who.int/cancer/detection/breastcan cer/en/index1.html available at 04.10.2015].

2. Oncological committee of the Romanian Health Ministry 2009. "Ghid de management al cancerului mamar" [www.ms.ro/documente/Ghid\%209_8292_6018 .doc available at 04.10.2015].

3. World Health Organisation. 2012. "Early detection of common cancers. Breast cancer". [http://www.euro.who.int/en/healthtopics/noncommunicablediseases/cancer/news/news/2012/2/earlydetection-of-common-cancers/breast-cancer available at 04.10.2015].

4. Mancini AD, Bonanno GA. Predictors and parameters of resilience to loss: Toward an

individual differences model. J Pers 2009; 77:1805-1832.

5. Bultz BD, Carlson LE. Emotional distress. The sixth vital sign in cancer care. J Clin Oncol 2005; 23:6440-6441.

6. Bultz BD, Carlson LE. Emotional distress: The sixth vital sign-future directions in cancer care. Psychooncology 2006; 15:93-95.

7. Holland JC, Bultz BD. The NCCN guideline for distress management: A case for making distress the sixth vital sign. J Natl Compr Canc Netw 2007; 5:3-7.

8. Richards, MA. Factors predicting delayed presentation of symptomatic breast cancer: a systematic review. Lancet 1999; 353(9159):1127-1131.

9. Romanian Cancer League. 2010 Save Women [http://romaniancancerleague.org/english/?pag e_id $=8$ available at 04.10.2015]. 
10. Ciornia O. 2011. Tumorile mamare pot fi tratate în ambulatoriu în România. [http://www.paginamedicala.ro/stirimedicale/Tumorile-mamare-pot-fi-tratate-inambulatoriu_-in-Romania_13240/ available at 04.10.2015].

11. Friedman LC, Mamta K, Richard E, et al. Medical and Psychosocial Predictors of Delay in Seeking Medical Consultation for Breast Symptoms in Women in a Public Sector Setting. J Behav Med 2006; 29:327-334.

12. Melnyk D, Shepperd JA. Avoiding risk information about breast cancer. Ann Behav Med 2012; 44:216-224.

13. Drageset S, Lindstrøm TC, Underlid K. Coping with breast cancer: between diagnosis and surgery. J Adv Nurs 2010; 66(1):149-158.

14. DC: American Psychiatric Association. Diagnostic and statistical manual of mental disorders. 5th Edition. Washington; 2013.

15. Stanton AL, Snider PR. Coping with a breast cancer diagnosis: A prospective study. Health Psycho 1993; 12:16-23.

16. Hoffman MA, Lent RW, Raque-Bogdan TL. A Social Cognitive Perspective on Coping With Cancer Theory, Research, and Intervention. Couns Psychol 2013; 41(2):240-267.

17. Lebel S, Jakubovits G, Rosberger Z, et al. Waiting for a breast biopsy. Psychosocial consequences and coping strategies. J Psychosom Res 2003; 55:437-443.

18. Hack, Thomas F, Lesley F. Coping responses following breast cancer diagnosis predict psychological adjustment three years later. Psychooncology 2004; 13(4):235-247.

19. Stanton AL, Danoff-Burg S, Huggins ME. The first year after breast cancer diagnosis: hope and coping strategies as predictors of adjustment. Psychooncology 2002; 11(2):93102.

20. Katz S, Lantz PM, Janz NK, et al. Patient Involvement In Surgery Treatment Decisions For Breast Cancer. J Clin Oncol 2005; 23(24):5526-533.

21. Lantz PM, Janz NK, Fagerlin $A$, et al. Satisfaction with Surgery Outcomes and the Decision Process in a Population-Based Sample of Women with Breast Cancer. Health Serv Res 2005; 40(3):745-68.

22. Faden RR, Beauchamp TL. A History and Theory of Informed Consent. New York: Oxford University Press, 1986.

23. Sutherland HJ, Llewellyn-Thomas $H A$, Lockwood GA, Tritchler DL, Till JE. Cancer patients: their desire for information and participation in treatment decisions. $J R$ Soc Med 1989; 82:260-263.

24. Andersen MR, Bowen DJ, Morea J, Stein KD, Baker F. Involvement in Decision-making and Breast Cancer Survivor Quality of Life. Health Psychol 2009; 28:29-37.

25. Livaudais JC, Franco R, Kezhen F, Bickell NA. Breast Cancer Treatment Decision-making: Are We Asking Too Much of Patients? J Gen Intern Med 2012; 28(5):630-36.

26. Nattinger AB, Gottlieb MS, Veum J, Yahnke D, Goodwin JS. Geographic variation in the use of breast-conserving treatment for breast cancer. N Eng J Med 1992; 326(17):1102-1107.

27. Schneider $\mathrm{C}$. The Practice of Autonomy: Patients, Doctors, and Medical Decisions. New York: Oxford Unviersity Press, 1998.

28. Rowland $\mathrm{JH}$, Massie MJ. Breast Cancer In Holland J (ed), Psycho-Oncolog. New York: Oxford University Press, 2010; 177-186.

29. Epstein RM, Street RL Jr. Patient-centered communication in cancer care: Promoting healing and reducing suff ering. National Cancer Institute, 2007.

30. Strull WM, Lo B, Charles G. Do patients want to participate in medical decision making?. JAMA 1984; 252:2990-2994.

31. Singh JA, Sloan JA, Atherton PJ, et al. Preferred roles in treatment decision making among patients with cancer: a pooled analysis of studies using the Control Preferences Scale. Am J Manag Care 2010; 16(9):688-696.

32. Fernandes-Taylor S, Bloom JR. Post-treatment regret among young breast cancer survivors. Psychooncology 2011; 20(5):506-516.

33. Sepucha KR, Feibelmann S. Breast Cancer Surgery Decision Quality Instrument User Guide, 2013. [http://www.massgeneral.org/decisionsciences/r esearch/ available at 04.10.2015].

34. Ferrans C, Powers M. Quality of Life Index: Development and psychometric properties. Advances in Nursing Science. 1985; 8:15-24. [https://www.uic.edu/orgs/qli/questionaires/pdf/c ancerversionlll/cancerenglish.pdf available at 04.10.2015].

35. Fagerlin A, Lakhani I, Lantz PM, et al. An Informed Decision? Breast Cancer Patients and Their Knowledge about Treatment. Patient Educ Couns 2006; 64(13):303-12.

36. Daltroy LH. Doctor-patient Communication in Rheumatological Disorders. Baillieres Clin Rheumatol 1993; 7:221-39. 